\title{
NOTES
}

\section{Ultrasound-Assisted Synthesis of Aromatic Polyformals from Bisphenols and Methylene Bromide}

\author{
Shinji Watanabe, Isao Matsubara, Masa-aki KaKimoto, \\ and Yoshio ImaI* \\ Department of Organic and Polymeric Materials, Tokyo Institute of Technology, \\ Meguro-ku, Tokyo 152, Japan
}

(Received March 31, 1993)

KEY WORDS Polyformals / Ultrasound Synthesis / Phase Transfer Catalyst /

\begin{abstract}
Recently ultrasound irradiation has widely been used for organic and organometallic syntheses. $^{1-4}$ The application of sonochemistry to polymer synthesis has also been investigated such as radical polymerizations of methyl methacrylate ${ }^{5,6}$ and diallyl terephthalate. ${ }^{7}$ However there are only a few reports on the syntheses of the condensation polymers such as polythiophene by electrochemical polymerization $^{8}$ and polysilane from dichlorosilane and metallic sodium. ${ }^{9}$ Since ultrasound accelerates many heterogeneous reactions in organic syntheses, ${ }^{10,11}$ it will also assist polycondensation in a heterogeneous system. Recently we have reported the ultrasound-assisted synthesis of polyarylates by the two-phase polycondensation from bisphenols and aromatic dicarboxylic acid chlorides. $^{12}$

Hay and his group reported the synthesis of the aromatic polyformal from bisphenol A [2,2'-bis(4-hydroxyphenyl)propane] and methylene halides in solid-liquid system. ${ }^{13,14} \mathrm{We}$ wish to report herein the synthesis of aromatic polyformals under ultrasonic irradiation from bisphenols and methylene bromide [(eq 1)].
\end{abstract}

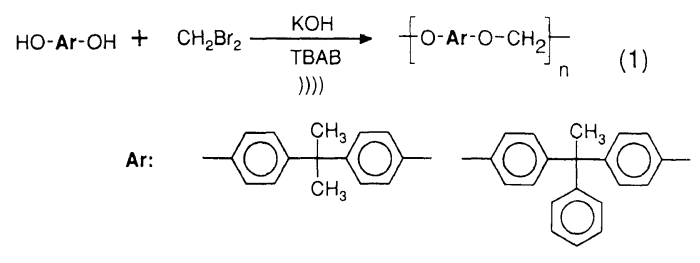

\section{EXPERIMENTAL PART}

\section{Materials and Apparatus}

Bisphenol A, bis(4-hydroxyphenyl)phenylethane (bisphenol AP), bis(4-hydroxyphenyl) sulfone (bisphenol S), and 4,4'-biphenol were recrystallized from toluene, tolueneethanol, ethanol, and ethanol, respectively. The other reagents including methylene bromide were used as received. As the source of ultrasound, a commercial ultrasonic cleaning bath (Tokyo Ultra Sonic Equipment Co., UC-0515 type) was used with a frequency of $27 \mathrm{kHz}$ and a power output of $150 \mathrm{~W}$.

\section{General Polymerization Procedure}

Into a three-neck flask, $5.00 \mathrm{~g}(22 \mathrm{mmol})$ of bisphenol A, $3.5 \mathrm{~g}(11 \mathrm{mmol})$ of tetrabutylammonium bromide (TBAB), and $3.6 \mathrm{~g}$ $(50 \mathrm{mmol})$ of powdered potassium hydroxide were placed and the mixture were suspended in $32 \mathrm{ml}$ of methylene bromide under nitrogen. The flask was placed onto the center of the 
bath and its vertical optimum position was determined by observation of the maximum surface disturbance with ultrasonic power. The mixture was stirred with a mechanical stirrer at $30^{\circ} \mathrm{C}$ for $4.5 \mathrm{~h}$ under ultrasonic irradiation. The polymer solution formed was diluted with $20 \mathrm{ml}$ of methylene chloride and washed with water. The organic layer was concentrated to $20 \mathrm{ml}$ under reduced pressure and poured into methanol to precipitate the polymer. After filtration, the resulting polymer was dried under vacuum. The yield of the polymer was $4.3 \mathrm{~g}(81 \%)$, and the inherent viscosity was $0.53 \mathrm{dl} \mathrm{g}^{-1}$ in $N$-methyl-2-pyrrolidone (NMP) at $30^{\circ} \mathrm{C}$.

IR (film): $1100 \mathrm{~cm}^{-1}(\mathrm{C}-\mathrm{O}-\mathrm{C})$.

${ }^{1} \mathrm{H}$ NMR $\left(\mathrm{CDCl}_{3}\right): \delta=1.63\left(\mathrm{~s}, 6 \mathrm{H}, \mathrm{C}_{3}\right)$, $5.64\left(\mathrm{~s}, 2 \mathrm{H}, \mathrm{CH}_{2}\right)$, and $6.9-7.2(\mathrm{~m}, 8 \mathrm{H}, \mathrm{Ar})$.

\section{Measurements}

IR and ${ }^{1} \mathrm{H}$ NMR spectra were recorded on a Shimadzu FTIR-8100M spectrophotometer and a JEOL FX-90Q spectrometer, respectively.

\section{RESULTS AND DISCUSSION}

First, the polycondensations giving aromatic polyformal were performed with two kinds of methylene halides and bisphenol $\mathrm{A}$ in the presence of powdered potassium hydroxide and TBAB as a phase transfer catalyst (PTC) with or without ultrasonic irradiation. The results of the polycondensations are summarized in Table I. It is obvious that ultrasonic irradiation was highly effective for the polycondensation over the polymerization under silent conditions and gave the polymer with higher viscosity values in higher yields. In case of the polycondensation with methylene chloride, the inherent viscosities of the polymer were lower than those by the polymerization with methylene bromide even though the polymerization was conducted at $50^{\circ} \mathrm{C}$. This is consistent with the fact that methylene bromide is more reactive than methylene chloride for nucleophilic substitution. The amount of the PTC also affected the polymer yield and viscosity. An increase of the ratio of TBAB to bisphenol A brought about the polymer with both higher yield and higher viscosity. The polycondensation without PTC yielded no polymer. There are many reports that ultrasonic irradiation accelerated heterogeneous reactions and, in some cases, ultrasound provided similar results to the reactions using PTC. ${ }^{10}$ Unfortunately, the ultrasonic wave did not act as a PTC in this system.

In the above-mentioned systems, some results of the polymerizations were poor

Table I. Synthesis of polyformal from bisphenol A with or without ultrasound irradiation ${ }^{\mathrm{a}}$

\begin{tabular}{|c|c|c|c|c|c|c|c|}
\hline \multirow{3}{*}{$\frac{\text { TBAB/Bisphenol }}{\text { Mole ratio }}$} & \multirow{3}{*}{$\mathrm{CH}_{2} \mathrm{X}_{2}$} & \multirow{3}{*}{$\frac{\text { Temperature }}{{ }^{\circ} \mathrm{C}}$} & \multirow{3}{*}{$\frac{\text { Time }}{\mathrm{h}}$} & \multicolumn{2}{|c|}{ Sonic $^{b}$} & \multicolumn{2}{|c|}{ Silent $^{c}$} \\
\hline & & & & Yield & $\eta_{\mathrm{inh}}^{\mathrm{d}}$ & Yield & $\eta_{\mathrm{inh}}{ }^{\mathrm{d}}$ \\
\hline & & & & $\%$ & $\overline{\mathrm{dlg}^{-1}}$ & $\%$ & $\overline{\mathrm{dlg}^{-1}}$ \\
\hline 0.5 & $\mathrm{Cl}$ & 50 & 1.5 & 93 & 0.32 & 68 & 0.14 \\
\hline 0.5 & $\mathrm{Cl}$ & 30 & 4.5 & 93 & 0.23 & - & - \\
\hline 0.5 & $\mathrm{Br}$ & 30 & 4.5 & 81 & 0.53 & 69 & 0.17 \\
\hline 0.2 & $\mathrm{Br}$ & 30 & 4.5 & 73 & 0.39 & 52 & 0.26 \\
\hline 0.1 & $\mathrm{Br}$ & 30 & 4.5 & 19 & 0.28 & - & - \\
\hline
\end{tabular}

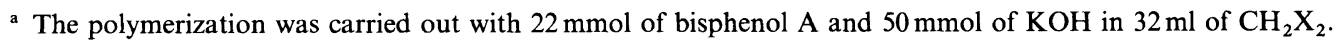

b The polymerization with ultrasonic irradiation.

c The polymerization without ultrasonic irradiation.

${ }^{d}$ Measured at a concentration of $0.5 \mathrm{dl} \mathrm{g}^{-1}$ in NMP at $30^{\circ} \mathrm{C}$. 
reproducibility, because a small amount of water in potassium hydroxide and TBAB might affect the polymer reaction. And we sometimes encountered that the polymer obtained was insoluble in all common organic solvents, and this made us confused to study the ultrasonic effect. This phenomenon may be explained by a probable crosslinking reaction like aromatic electrophilic substitution as shown in eq 2 .

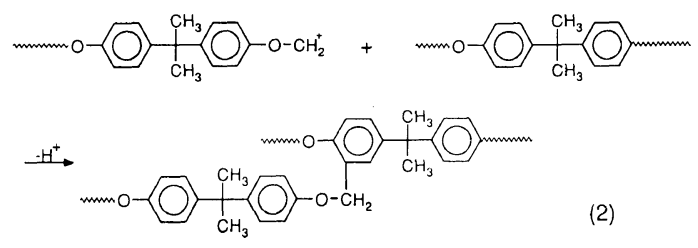

Hence we investigated further polycondensations in the presence of a small amount of water, in order to determine the optimum conditions for the ultrasonic effect. Figure 1 shows the effect of amount of water on the yield and inherent viscosity of the polymer. Both the yield and viscosity of the polymer increased with a decrease of the amount of water. In case of the polycondensation with $20 \mathrm{ml}$ of water, the polymer was not obtained at all, because of good solubility of the potassium salt of bisphenol $\mathrm{A}$ in water. On the other hand, the polymerization using $2.5 \mathrm{ml}$ or

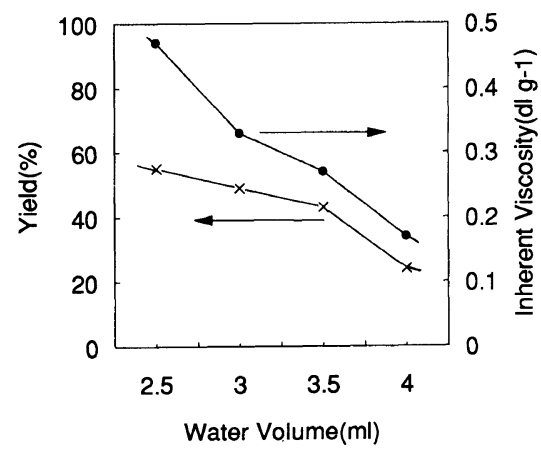

Figure 1. The effect of amount of water on yield $(*)$ and inherent viscosity (- - ) of the polymer. The polymerization was carried out with $22 \mathrm{mmol}$ of bisphenol A, $50 \mathrm{mmol}$ of $\mathrm{KOH}$, and $11 \mathrm{mmol}$ of TBAB in $5 \mathrm{ml}$ of $\mathrm{CH}_{2} \mathrm{Br}_{2}$ and $15 \mathrm{ml}$ of chlorobenzene at $30^{\circ} \mathrm{C}$ for $1 \mathrm{~h}$ under ultrasonic irradiation.
$3.0 \mathrm{ml}$ of water yielded the polymer having some insoluble fraction, which led to poor reproducibility of the polymerization. Therefore, further polycondensations were carried out with $3.5 \mathrm{ml}$ of water. The yields and inherent viscosities of the obtained polymer with or without ultrasonic irradiation are shown in Figure 2. It is again evident that both the yield and inherent viscosity of the polymer were higher in the polycondensation with ultrasonic irradiation than those in the silent polymerization. The ultrasound may promote the polycondensation by the cavitation effect

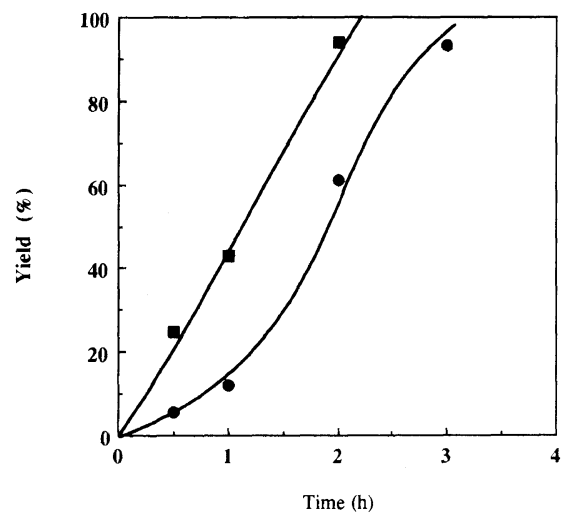

(a)

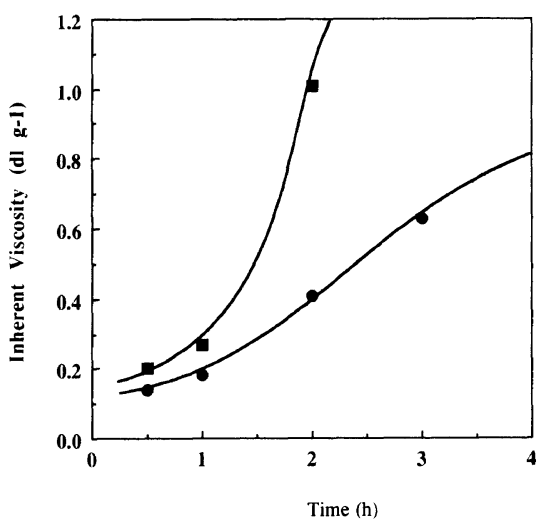

(b)

Figure 2. The effect of ultrasonic irradiation on yield (a) and inherent viscosity (b) of the polymer. The polymerization was carried out with $22 \mathrm{mmol}$ of bisphenol A, $50 \mathrm{mmol}$ of $\mathrm{KOH}, 11 \mathrm{mmol}$ of TBAB in $3.5 \mathrm{ml}$ of water, $5 \mathrm{ml}$ of $\mathrm{CH}_{2} \mathrm{Br}_{2}$, and $15 \mathrm{ml}$ of chlorobenzene at $30^{\circ} \mathrm{C}$ with ( $-\square-$ ) or without (-O) ultrasonic irradiation. 
Table II. Syntheses of polyformals from various bisphenols with or without ultrasound irradiation ${ }^{a}$

\begin{tabular}{|c|c|c|c|c|c|}
\hline \multirow{3}{*}{ Bisphenol } & \multirow{3}{*}{$\frac{\text { Time }}{\mathrm{h}}$} & \multicolumn{2}{|c|}{ Sonic $^{\mathbf{b}}$} & \multicolumn{2}{|c|}{ Silent $t^{c}$} \\
\hline & & Yield & $\eta_{\mathrm{inh}}^{\mathrm{d}}$ & Yield & $\eta_{\mathrm{inh}}^{\mathrm{d}}$ \\
\hline & & $\%$ & $\mathrm{dl} \mathrm{g}^{-1}$ & $\%$ & $\mathrm{dl} \mathrm{g}^{-1}$ \\
\hline A & 2 & 94 & 1.01 & 61 & 0.41 \\
\hline AP & 4 & 100 & 0.21 & 60 & 0.09 \\
\hline
\end{tabular}

a The polymerization was carried out with $22 \mathrm{mmol}$ of the bisphenol, $50 \mathrm{mmol}$ of $\mathrm{KOH}$, and $11 \mathrm{mmol}$ of TBAB in $3.5 \mathrm{ml}$ of water, $5 \mathrm{ml}$ of $\mathrm{CH}_{2} \mathrm{Br}_{2}$, and $15 \mathrm{ml}$ of chlorobenzene at $30^{\circ} \mathrm{C}$.

b,c,d See footnotes b, c, and d of Table I.

of emulsification. ${ }^{11}$ The polymer having high inherent viscosity around $1.0 \mathrm{dlg}^{-1}$ could be obtained by the polycondensation under sonication at $30^{\circ} \mathrm{C}$ for $2 \mathrm{~h}$. The IR and ${ }^{1} \mathrm{H}$ NMR spectra of the polymer obtained by the ultrasonic polymerization were consistent with those without ultrasonic irradiation, and this confirmed the formation of aromatic polyformal.

Some kinds of polymers were known to degrade to lower molecular weight polymers by ultrasonic irradiation. ${ }^{15}$ In order to learn the susceptibility of ultrasonic degradation of the polymer, the polyformal with an inherent viscosity of $0.99 \mathrm{dl} \mathrm{g}^{-1}$ in methylene bromidechlorobenzene solution was subjected to the ultrasonic wave at $30^{\circ} \mathrm{C}$ for $2 \mathrm{~h}$. The inherent viscosity of the recovered polymer after ultrasonic irradiation did not change at all. This may be attributed to low power of the ultrasonic cleaning bath used in this study.

We also synthesized the other aromatic polyformal from bisphenol AP by the ultrasound-assisted polycondensation (Table II). The polycondensation of bisphenol AP and methylene bromide yielded the polymer quanti- tatively. In this case, ultrasound also accelerated the polymerization. The other polyformals from bisphenol $\mathrm{S}$ or 4,4 '-biphenol could not be obtained under these polymerization conditions. These may be due to low nucleophilicity of the former bisphenol and low solubility in the organic solvent of the latter bisphenol salt.

In conclusion, the polycondensations of bisphenol A and bisphenol AP with methylene bromide gave the aromatic polyformals with high inherent viscosity at $30^{\circ} \mathrm{C}$ for $2-5 \mathrm{~h}$ under ultrasonic irradiation. In these cases, ultrasound assisted the polymer forming reaction.

\section{REFERENCES}

1. C. Einhorn, J. Einhorn, and J.-L. Luche, Synthesis, 787 (1989).

2. S. V. Ley and C. M. R. Low, "Ultrasound in Synthesis," Springer-Verlag, Berlin, 1989.

3. T. J. Mason and J. P. Lorimer, "Sonochemistry," Ellis Horwood, England, 1989.

4. T. J. Mason, "Practical Sonochemistry," Ellis Horwood, England, 1991.

5. P. Kruus and T. J. Patraboy, J. Phys. Chem., 89, 3379 (1985).

6. G. J. Price, D. J. Norris, and P. J. West, Macromolecules, 25, 6447 (1992).

7. H. Fujiwara and K. Goto, Polym. Bull., 25, 571 (1991).

8. S. Osawa, M. Ito, K. Tanaka, and J. Kuwano, $J$. Polym. Sci., B, Polym. Phys., 30, 19 (1992).

9. H. K. Kim and K. Matyjaszewski, J. Am. Chem. Soc., 110, 3321 (1988).

10. S. L. Regen and A. Singh, J. Org. Chem., 47, 1587 (1982).

11. S. Moon, L. Duchin, and J. V. Cooney, Tetrahedron Lett., 41, 3917 (1979).

12. G.-S. Liou, M. Kakimoto, and Y. Imai, J. Polym. Sci., A, Polym. Chem., 30, 2195 (1992).

13. A. S. Hay, F. J. Williams, H. M. Relles, B. M. Boulette, P. E. Donahue, and D. S. Johnson, J. Polym. Sci., Polym. Lett. Ed., 21, 449 (1983).

14. A. S. Hay, F. J. Williams, H. M. Relles, and B. M. Boulette, J. Macromol. Sci.-Chem., A21, 1065 (1984).

15. G. J. Price, Advances in Sonochemistry, 1, 231 (1990). 